\title{
Potassium channels are involved in testosterone-induced vasorelaxation of human umbilical artery
}

\author{
Elisa Cairrão • Ezequiel Álvarez • \\ António José Santos-Silva • Ignacio Verde
}

Received: 9 July 2007 / Accepted: 28 October 2007 / Published online: 20 November 2007

(C) Springer-Verlag 2007

\begin{abstract}
Recent studies have shown that testosterone induces relaxation of different arteries, although the mechanism of this action is still under debate. We investigated the involvement of potassium channels in this mechanism. Using standard organ bath techniques, rings of human umbilical arteries (HUA) without endothelium were contracted by serotonin $(5-\mathrm{HT}, 1 \mu \mathrm{M})$, histamine $(10 \mu \mathrm{M})$ and potassium chloride $(\mathrm{KCl}, 30$ and $60 \mathrm{mM})$, and the vasorelaxant effect of testosterone was analysed. Testosterone $(100 \mu \mathrm{M})$ relaxed human umbilical arteries contracted with 5 -HT $(30.1 \pm 3.2 \%)$, histamine $(55.1 \pm 2.6 \%), \mathrm{KCl}$ $30 \mathrm{mM}(52.9 \pm 8.3 \%)$ and $\mathrm{KCl} 60 \mathrm{mM}(54.8 \pm 6.3 \%)$. Flutamide $(10 \mu \mathrm{M})$, an inhibitor of classical intracellular testosterone receptor, and glibenclamide, an ATP-sensitive potassium-channels $\left(\mathrm{K}_{\mathrm{ATP}}\right)$ inhibitor, did not influence the testosterone relaxant effect. 4-aminopyridine, a voltagesensitive potassium-channels $(\mathrm{Kv})$ inhibitor, decreased the effect of testosterone on histamine- and 5-HT-contracted arteries. Tetraethylammonium (TEA), which inhibits $\mathrm{Kv}$ channels and large-conductance $\mathrm{Ca}^{2+}$-activated potassium channels $\left(\mathrm{BK}_{\mathrm{Ca}}\right)$, decreased the effect of testosterone on $\mathrm{KCl}(60 \mathrm{mM})$-contracted and 5-HT-contracted HUA. In conclusion, testosterone induces relaxation of HUA, and this effect does not appear to be mediated via a classic
\end{abstract}

\footnotetext{
E. Cairrão • E. Álvarez • A. J. Santos-Silva • I. Verde $(\bowtie)$ CICS - Centro de Investigação em Ciências da Saúde, Universidade da Beira Interior,

Av. Infante D. Henrique, 6200-506 Covilhã, Portugal

e-mail: iverde@fcsaude.ubi.pt

E. Cairrão

Centro Hospitalar da Cova da Beira E.P.E.,

Quinta do Alvito,

6200-251 Covilhã, Portugal
}

intracellular testosterone receptor-dependent mechanism. Our results suggest that this relaxation is partially mediated by activation of $\mathrm{BK}_{\mathrm{Ca}}$ and $\mathrm{K}_{\mathrm{V}}$ channels. The involvement of these two channels in testosterone-relaxant mechanism is dependent on the pathways activated by the contractile agent used.

Keywords Human umbilical artery · Testosterone . Potassium channels $\cdot$ Vasorelaxation

\section{Introduction}

Human umbilical artery (HUA) is involved in fetoplacental circulation. Endocrine and paracrine mechanisms that regulate the contractile state of smooth muscle cells are very important for optimum gas and nutrient exchange between the foetus and the placenta, since the umbilical blood vessels are not innervated. Thus, it is important to characterise the mechanisms that regulate umbilical vessel tone and to know which factors regulate blood flow in the umbilical circulation. During pregnancy, there is an increase in the amounts of some circulating sex steroid hormones, such as androgens, which show a higher concentration in the umbilical artery than in the umbilical vein, indicating that these androgens are produced mainly in the foetal compartment (Pasqualini 2005).

Gender differences in the incidence of cardiovascular health problems have been attributed to different sex hormonal patterns found in women and men. Recent studies illustrate that testosterone (Tes) has beneficial cardiovascular effects, and several epidemiological studies also indicated that patients with cardiovascular diseases have low levels of Tes (Alexandersen et al. 1996; English et al. 2000a, b, c; Tammaro et al. 2004). Moreover, hypotestos- 
teronemia was associated with an atherogenic lipid profile, high fibrinogen levels, an increase in insulin resistance, hyperinsulinemia and higher systolic and diastolic blood pressure levels (English et al. 2000a; Pinthus et al. 2006). However, an increase in maternal serum androgen concentration during pregnancy was also associated with preeclampsia (Salamalekis et al. 2006) and pregnancy-induced hypertension (Gerulewicz-Vannini et al. 2006).

Some recent studies have demonstrated that Tes acts as direct vasodilator in a variety of species and blood vessels (Orshal and Khalil 2004), including human arteries (Malkin et al. 2006; Yildiz et al. 2005). The rapid vascular effects of Tes suggest the involvement of mechanisms related to membrane receptors and independent of the classic genomic pathway (Orshal and Khalil 2004).

The participation of the endothelium in Tes vascularrelaxant mechanism has also been analysed by different authors. Yue et al. indicated that Tes induces endotheliumindependent relaxation in isolated rabbit coronary artery and aorta, which is mediated neither by prostaglandin $\mathrm{I}_{2}$ nor cyclic GMP (Yue et al. 1995). Tes-induced relaxation of porcine coronary arteries was associated with accumulation of cGMP by an endothelium-independent mechanism (Deenadayalu et al. 2001). However, other works showed that removal of the endothelium reduces the Tes relaxant effect in aorta (Ding and Stallone 2001) and mesenteric artery (Tep-areenan et al. 2002; Tep-areenan et al. 2003) of rats.

The mechanism of Tes in smooth muscle cells is still unclear. Some authors suggested that the relaxant effect of Tes is induced by a blockade of smooth muscle calcium channels in rat aorta (Perusquia and Villalon 1999), pig coronary artery (Crews and Khalil 1999; Murphy and Khalil 1999) and rat pulmonary artery (Jones et al. 2002). More specifically, Perusquia et al. suggested that inhibition of receptor-operated calcium channels in rat aorta might be the mechanism that induces androgen-associated relaxing effects (Perusquia et al. 1996). Recently, the inhibition of voltage-dependent calcium channels by Tes was demonstrated by authors working with rat pulmonary artery (Jones et al. 2002) and with A7r5 cells from rat aorta (Hall et al. 2006). In contrast, several authors showed that Tes-induced relaxant effect is due to activation of smooth muscle potassium channels in rat aorta (Ding and Stallone 2001; Honda et al. 1999), pig coronary artery (Deenadayalu et al. 2001) and rabbit coronary artery (Yue et al. 1995). The activation of several potassium channel types was involved in Tes-associated relaxant effect in different arteries, such as $\mathrm{K}_{\mathrm{ATP}}$ channels in dog coronary artery (Chou et al. 1996) and rat aorta (Honda et al. 1999) and $\mathrm{BK}_{\mathrm{Ca}}$ channels in human internal mammary artery (Yildiz et al. 2005). When proposing a vasodilatory mechanism for Tes, the discrepancy between these results is evident, but differences in species and vascular preparations used have likely contributed to these discrepancies.

In our study, we focus on the endothelium-independent vascular mechanisms of Tes-induced vasorelaxation in HUA when these arteries are contracted by depolarisation with $\mathrm{KCl}$, or by histamine (His) and serotonin (5-HT) receptor activation. The involvement of the classic intracellular Tes receptor and different potassium channel types on the Tes relaxant effect was analysed.

\section{Methods}

Tissue preparation

Umbilical cord pieces of 3-7 $\mathrm{cm}$ were obtained from normal term pregnancies with the consent of the donor mothers. All procedures carried out with these samples were approved by the Ethics Committee of Centro Hospitalar da Cova da Beira EPE. The umbilical cord samples were collected in sterile physiological saline solution (PSS) [composition (mM): $\mathrm{NaCl} 110, \mathrm{CaCl}_{2} 0.15$, $\mathrm{KCl} 5, \mathrm{MgCl}_{2}$ 2, HEPES 10, $\mathrm{NaHCO}_{3} 10, \mathrm{KH}_{2} \mathrm{PO}_{4} 0.5$, $\mathrm{NaH}_{2} \mathrm{PO}_{4}$ 0.5, glucose 10, EDTA 0.49]. In order to avoid contamination and tissue degradation, penicillin $(5 \mathrm{U} / \mathrm{ml})$, streptomycin $(5 \mu \mathrm{g} / \mathrm{ml})$, amphotericin B $(12.5 \mathrm{ng} / \mathrm{ml})$ and antiproteases (leupeptine $0.45 \mathrm{mg} / \mathrm{l}$, benzamidine $26 \mathrm{mg} / \mathrm{l}$ ) and trypsin inhibitor $(10 \mathrm{mg} / \mathrm{l})$ were added to the PSS solution. Umbilical artery rings of 3-5 $\mathrm{mm}$ were isolated from the surrounding connective tissue. Vascular endothelium was mechanically removed by gentle rubbing with a cotton bud introduced through the arterial lumen.

Artery tension recordings

The HUA rings were placed in an organ bath (LE01.004, Letica) containing Krebs-bicarbonate solution (composition in mM: $\mathrm{NaCl} 119, \mathrm{KCl} 5.0, \mathrm{NaHCO}_{3} 25, \mathrm{KH}_{2} \mathrm{PO}_{4} 1.2$, $\mathrm{CaCl}_{2}$ 0.5, $\mathrm{MgSO}_{4} 1.2$, EDTA 0.03 , glucose 11 ) at $37^{\circ} \mathrm{C}$ and continuously gassed with carbogen. The artery rings were suspended between two parallel stainless steel wires and tension measurement was performed using isometric transducers (TRI201, Panlab SA, Spain), amplifier (ML118/D Quad Bridge, ADInstruments), interface PowerLab/4SP (ML750, ADInstruments) and computerised system with Chart5 PowerLab software (ADInstruments). During the resting periods, the organ bath solution was changed every $15 \mathrm{~min}$. Initially, the rings were equilibrated for 60 min until a resting tension of $1.5 \mathrm{~g}$ was achieved. After this, the rings were challenged with 5-HT $(1 \mu \mathrm{M})$ to test their viability. Rings that induced contraction of less than $1 \mathrm{~g}$ when challenged with 5-HT were excluded from the study. Afterwards, HUA rings were contracted using 
$\mathrm{KCl}(30$ and $60 \mathrm{mM})$, His $(10 \mu \mathrm{M})$ or 5 -HT $(1 \mu \mathrm{M})$, and vasorelaxation induced by Tes $(1-100 \mu \mathrm{M})$ on these contractions was analysed. In some cases, the involvement of classical Tes receptors was examined using flutamide (Flu; $10 \mu \mathrm{M}$ ), an antagonist of these receptors. To determine the role of potassium-channels activation in Tes-induced vasorelaxation, several inhibitors were used: tetraethylammonium (TEA; $1 \mathrm{mM}$ ), an inhibitor of largeconductance $\mathrm{Ca}^{2+}$-activated $\left(\mathrm{BK}_{\mathrm{Ca}}\right)$ and voltage-sensitive $(\mathrm{Kv})$ potassium channels; glibenclamide (Gli; $10 \mu \mathrm{M})$, an ATP-sensitive potassium-channel $\left(\mathrm{K}_{\mathrm{ATP}}\right)$ inhibitor; and 4aminopyridine (4-AP; $1 \mathrm{mM}$ ), an inhibitor of voltagesensitive potassium $\left(\mathrm{K}_{\mathrm{V}}\right)$ channels.

\section{Drugs and chemicals}

All drugs and chemicals were purchased from SigmaAldrich Química (Sintra, Portugal), except 4-AP, which was purchased from Biogen Cientifica. (Madrid, Spain). Testosterone and Flu were initially dissolved in dimethyl sulfoxide (DMSO) and ethanol respectively, and final solutions were obtained by dilution with distilled water. The final concentration of both organic solvents in the organ bath did not exceed $0.1 \%$. Histamine, 5-HT, Gli, 4AP and TEA were dissolved in distilled water.

\section{Statistical analysis}

Statistical treatment of data was performed using the SigmaStat Statistical Analysis System, version 1.00 (1992). Results are expressed as mean \pm SEM of $n$ experiments. Relaxant Tes effects are given as percentage of decrease in the contraction induced by $\mathrm{KCl}$, His or 5-HT. Statistical significance between two groups was analysed using Student's $t$-test. Comparison among multiple groups was analysed by using a one-way ANOVA followed by Tukey test or Dunnet's post-hoc tests to determine significant differences among the means. Probability levels lower than $5 \%$ were considered significant $(P<0.05)$.

\section{Results}

Effect of Tes on contracted HUA

The HUA rings without endothelium were exposed to different receptor agonists and to depolarisation to analyse their sensitivity. Although noradrenaline $(1 \mu \mathrm{M})$ and angiotensin II $(1 \mu \mathrm{M})$ did not induce significant effects (data not shown), 5-HT $(1 \mu \mathrm{M})$ and His $(10 \mu \mathrm{M})$ elicited maximum contractile effects of 1,648.4 $\pm 67.2(n=90)$ and $1,296.8 \pm 57.3 \mathrm{mg}(n=86)$ respectively, which were significantly different $(P<0.05$, one-way ANOVA with Tukey post-hoc test). Different degrees of depolarisation, by $\mathrm{KCl}$ 30 and $60 \mathrm{mM}$, induced dissimilar degrees of maximum contraction: $1,009.9 \pm 87.0 \mathrm{mg}(n=13)$ and $1,413.9 \pm 62.2 \mathrm{mg}$ $(n=59)$ respectively $(P<0.05$, one-way ANOVA with Tukey post-hoc test). These last three contractile agents were used as previous stimuli to analyse the effect of Tes.

In general, Tes induced concentration-dependent vasorelaxations of HUA ring contracted with either 5-HT, His or $\mathrm{KCl}$ (Figs. 1 and 2a), and the time to reach the effect of each concentration was between 2 and $12 \mathrm{~min}$. DMSO, the vehicle used to dissolve Tes, did not have a significant relaxant effect on contracted arteries at the concentrations used. As shown in Fig. 1, the maximum relaxation induced by Tes $(100 \mu \mathrm{M})$ was similar in arteries treated with His or $\mathrm{KCl} 30$ and $60 \mathrm{mM}: 55.8 \pm 5.7 \%, 52.9 \pm 8.3 \%$ and $53.2 \pm$ $6.3 \%$ respectively $(P>0.05)$. The maximum Tes effect on 5 HT-contracted arteries was significantly lower $(30.1 \pm 3.2 \%)$ than that observed with His or $\mathrm{KCl}(P<0.05)$. However, the effect of Tes at lower concentrations $(1-30 \mu \mathrm{M})$ was significantly greater in arteries contracted by His than in 5-HT- or KCl-stimulated arteries $(P<0.05)$. In fact, Fig. 1 shows that Tes concentrations of 1 and $10 \mu \mathrm{M}$ induced significant relaxation only in His-stimulated arteries $(P<$ 0.05 and $P<0.01$ respectively). These results also show that the relaxant effects of Tes are more prominent in Hiscontracted HUA, and the lowest Tes effects were observed when the contractile agent used was 5-HT. The relaxations induced by the different concentrations of Tes $(1 \mu \mathrm{M}-$ $100 \mu \mathrm{M})$ on HUA contracted by $\mathrm{KCl} 30$ and $60 \mathrm{mM}$ were similar $(P>0.05)$.

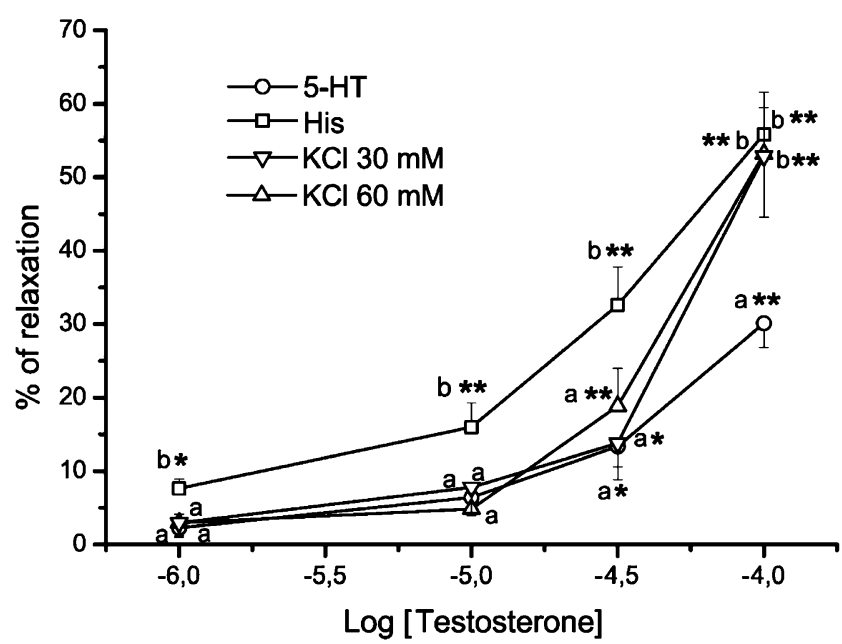

Fig. 1 Cumulative concentration-relaxation curves of testosterone (1$100 \mu \mathrm{M})$ in endothelium-denuded HUA rings contracted with serotonin $(5-\mathrm{HT} ; 1 \mu \mathrm{M})$, histamine $(\mathrm{His} ; 1 \mu \mathrm{M}), \mathrm{KCl}(30 \mathrm{mM})$ or $\mathrm{KCl}(60 \mathrm{mM})$. Each point represents the mean value and the vertical lines indicate SEM of at least five experiments. ${ }^{*} P<0.05$ versus control performed with vehicle, Student's $t$-test. Different letters $(a, b)$ indicate significant differences $(P<0.05$, one-way ANOVA with Tukey post-hoc test) between the effects induced by a concentration of testosterone on arteries contracted with different agents 
Fig. 2 Original tracing of $\mathrm{KCl}$ $(60 \mathrm{mM})$-contracted human umbilical artery rings showing the relaxation induced by different concentrations $(1-100 \mu \mathrm{M})$ of testosterone (Tes) in a absence and $\mathbf{b}$ presence of tetraethylammonium (TEA)
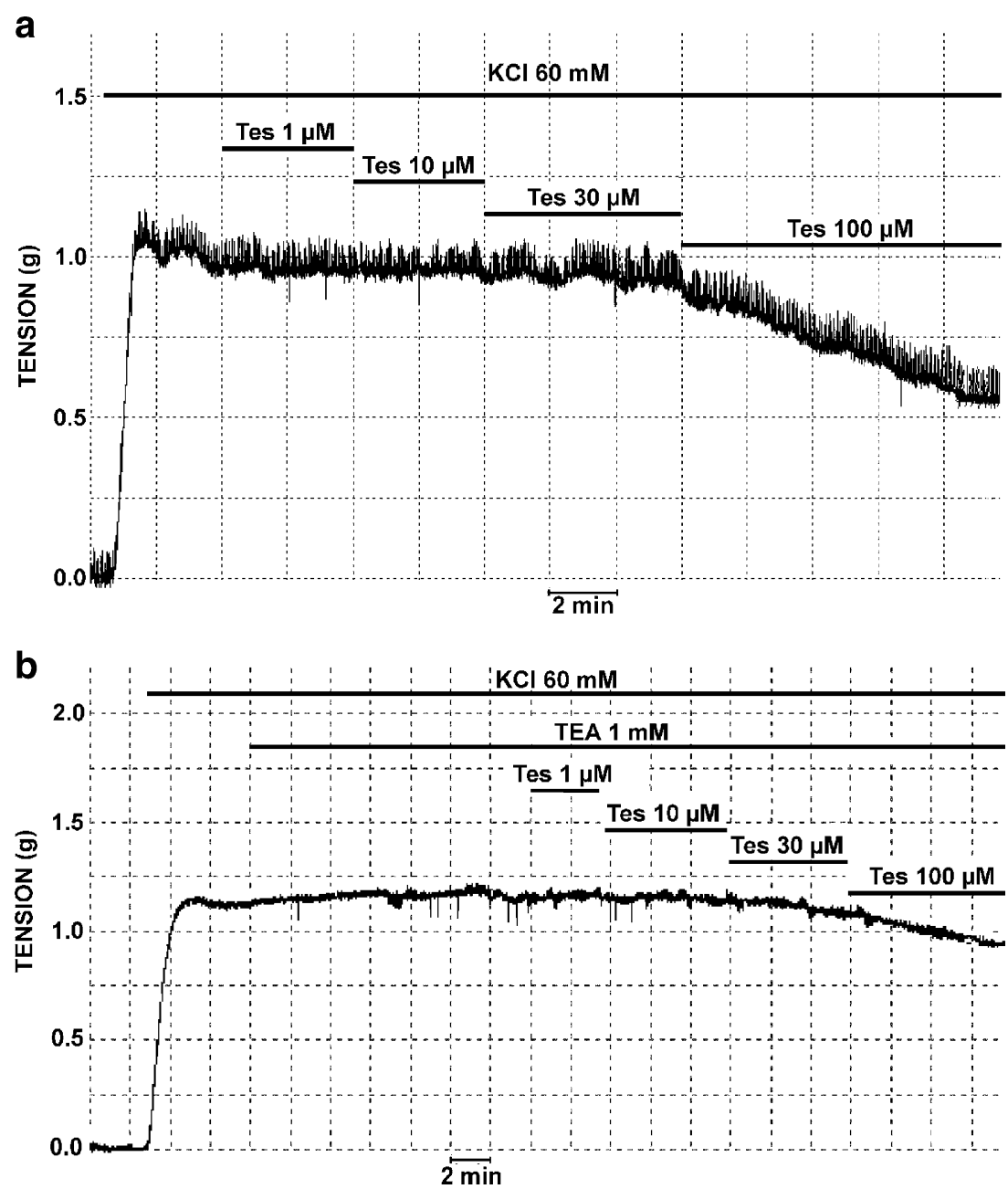

Flutamide, an inhibitor of the Tes classical intracellular receptor, was used to analyse the involvement of this receptor in the relaxing effect mediated by Tes. Flutamide alone did not induce a significant relaxation of contractions induced by 5-HT, His or $\mathrm{KCl} 60 \mathrm{mM}$ (Table 1). As shown in Fig. 3, flutamide $10 \mu \mathrm{M}$ did not significantly modify the Tes-associated relaxant effect on either 5-HT, His or $\mathrm{KCl}$ $(60 \mathrm{mM})$ contracted arteries $(P>0.05)$. Ethanol, the vehicle used to dissolve flutamide, did not have any effect at the concentrations used (data not shown). These data indicate that the effects of Tes are mediated by mechanisms other than activation of the classical intracellular Tes receptor.

The role of potassium channels in Tes-induced vasorelaxation

The effects of three potassium channel inhibitors (Gli, 4$\mathrm{AP}$, and TEA) were investigated to analyse the involvement of these channels in the Tes-associated relaxant mechanism. Initially, after contraction by the different agents, HUA were exposed for $15 \mathrm{~min}$ to Gli, 4-AP and TEA, either together or separately, and these inhibitors did not have a significant effect on the contraction induced by either 5-HT, His or $\mathrm{KCl} 60 \mathrm{mM}$ (Fig. 2b, Table 1).

As shown in Fig. 4, independently of the contractile stimuli, incubation with Gli, 4-AP and TEA together significantly reduced the maximum $(100 \mu \mathrm{M})$ Tes-associated relaxing effects. However this reduction was different depending on the contractile agent.

The application of Gli $(10 \mu \mathrm{M})$, which inhibits ATPsensitive potassium channels $\left(\mathrm{K}_{\mathrm{ATP}}\right)$, did not significantly

Table 1 Effect (\%; mean \pm SEM) of flutamide (Flu; $10 \mu \mathrm{M})$, glibenclamide (Gli; $10 \mu \mathrm{M})$, 4-aminopyridine (4-AP; $1 \mathrm{mM}$ ), and tetraethylammonium (TEA; $1 \mathrm{mM}$ ) on the contractions induced by serotonin $(5-\mathrm{HT} ; 1 \mu \mathrm{M})$, histamine (His; $1 \mu \mathrm{M})$ or $\mathrm{KCl}(60 \mathrm{mM})$

\begin{tabular}{llll}
\hline & 5-HT (\%) & His (\%) & KCl (\%) \\
\hline Flu & $-0.7 \pm 1.3(n=16)$ & $-1.4 \pm 1.9(n=12)$ & $0.4 \pm 2.8(n=8)$ \\
Gli & $0.8 \pm 1.0(n=36)$ & $-1.6 \pm 0.8(n=18)$ & $1.2 \pm 1.0(n=29)$ \\
4-AP & $0.3 \pm 1.1(n=10)$ & $-1.1 \pm 1.2(n=5)$ & $0.0 \pm 1.8(n=8)$ \\
TEA & $-0.4 \pm 0.7(n=10)$ & $0.4 \pm 2.9(n=9)$ & $0.3 \pm 3.6(n=9)$ \\
Gli+4- & $2.3 \pm 1.9(n=5)$ & $-2.4 \pm 0.6(n=5)$ & $-0.2 \pm 1.2(n=8)$ \\
AP+TEA & & & \\
\hline
\end{tabular}



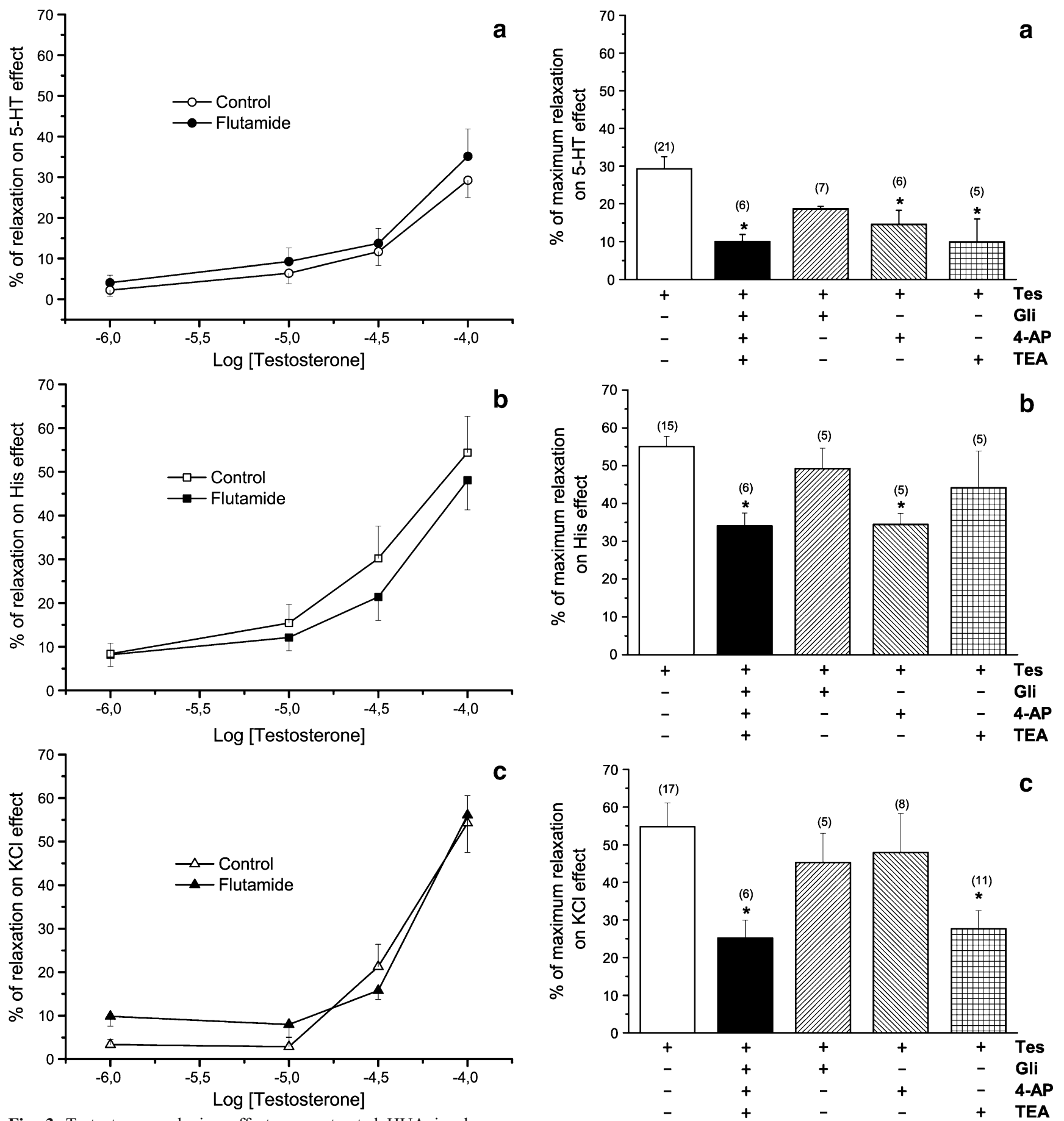

Fig. 3 Testosterone relaxing effect on contracted HUA in absence (open symbols) and presence (closed symbols) of flutamide $10 \mu \mathrm{M}$. Data are expressed as percentage of relaxation on arteries contracted with a $1 \mu \mathrm{M}$ serotonin (5-HT), b $1 \mu \mathrm{M}$ histamine (His) and c $60 \mathrm{mM}$ $\mathrm{KCl}$. Each point represents the mean and the vertical lines the SEM of at least five experiments

reduce the effects of Tes on 5-HT-, His- or KCl-contracted arteries $(P>0.05)$.

With regards to the role of the voltage-sensitive channels $\left(\mathrm{K}_{\mathrm{V}}\right)$, 4-AP $(1 \mathrm{mM})$ reduced the Tes-associated effect in 5HT- and His-contracted arteries $(P<0.05)$. However, this

Fig. 4 Effect of the potassium channel inhibitors glibenclamide (Gli; $10 \mathrm{\mu M})$, 4-aminopyridine (4-AP; $1 \mathrm{mM})$, and tetraethylammonium (TEA; $1 \mathrm{mM}$ ) on maximum testosterone relaxant effect in HUA contracted with a $1 \mu \mathrm{M}$ serotonin (5-HT), b $1 \mu \mathrm{M}$ histamine (His) and c $60 \mathrm{mM} \mathrm{KCl}$. Data are expressed as percent of inhibition on the contractile effects, the bars represent the mean and the lines the SEM of the number of experiments indicated near the bars. ${ }^{*} P<0.05$ versus testosterone effects in absence of any channel inhibitor, one-way ANOVA with Dunnet's post-hoc test

drug did not significantly reduce the Tes-induced relaxation of KCl-contracted arteries as shown in Fig. $4(P>0.05)$. 
TEA, an inhibitor of $\mathrm{BK}_{\mathrm{Ca}}$ and $\mathrm{Kv}$ channels, significantly reduced the relaxant effect of Tes on 5-HT- and $\mathrm{KCl}$-stimulated arteries, but its action to reduce the effect of Tes was not significant in His-contracted arteries (Figs. 2b and 4).

\section{Discussion}

As expected and in accordance with other authors (Quan et al. 2003), our results show that the contraction induced by $\mathrm{KCl}(30 \mathrm{mM})$ was smaller than that induced by $\mathrm{KCl}$ $(60 \mathrm{mM})$ because the depolarisation degree is different. Maximum contractions caused by 5 - $\mathrm{HT}$ and $\mathrm{KCl}(60 \mathrm{mM})$ in HUA are not significantly different. This has already been reported by some authors (Leung et al. 2006), although other investigators indicated that 5-HT-induced contraction is greater than that produced by $\mathrm{KCl}$ depolarisation (Tufan et al. 2003). However, the tension produced by His was lower than that induced by 5 -HT, results that are in agreement with those of Quan et al. (2003).

The different mechanisms implicated in the contractile effect of these agents could explain the results. Vascular contraction induced by $\mathrm{KCl}$ is mainly due to the influx of extracellular calcium via voltage-dependent calcium channels (Tufan et al. 2003), but Kv-channel inactivation at high potassium concentrations $(60 \mathrm{mM})$ was also demonstrated in some blood vessels (Jarajapu et al. 2006). The contractile effects of 5-HT in denuded HUA are due to the activation of the receptors 5- $\mathrm{HT}_{1 \mathrm{~B}}$ and 5- $\mathrm{HT}_{2 \mathrm{~A}}$ (Lovren et al. 1999). The activation of 5- $\mathrm{HT}_{1 \mathrm{~B}}$ receptor inhibits adenylyl cyclase, and the $5-\mathrm{HT}_{2 \mathrm{~A}}$-receptor activation stimulates phospholipase $\mathrm{C}$, thereby increasing inositol 1,4,5-triphosphate $\left(\mathrm{IP}_{3}\right)$ levels (Pauwels 2000; Steinert et al. 2002; Tufan et al. 2003). Recently, using patch-clamp techniques, some authors demonstrated that $5-\mathrm{HT}_{2 \mathrm{~A}}$-receptor activation decreases $\mathrm{Kv}$-channel activity in cells of rat pulmonary (Cogolludo et al. 2006) and mesenteric (Bae et al. 2006) arteries. The $5-\mathrm{HT}_{7}$ receptors were also implicated in the endothelium-independent vasorelaxation of several blood vessels because their activation stimulates adenylyl cyclase (Jahnichen et al. 2005; Terron and Falcon-Neri 1999). However, expression of these receptors was not demonstrated in HUA.

In the case of His, activation of $\mathrm{H}_{1}$ receptors in HUA smooth muscle induces contraction by activation of phospholipase $\mathrm{C}$ and increase in $\mathrm{IP}_{3}$ levels (Hawley et al. 1995). The expression of $\mathrm{H}_{2}$ receptors in human umbilical smooth muscle was also reported by Schneider et al. (Schneider et al. 2004). The activation of this receptor stimulates adenylyl cyclase activity producing an increase in cyclic AMP and relaxation. Jarajapu et al. suggested that vasodilatation of rat cerebral resistance arteries by $\mathrm{H}_{2}$ - receptor activation may be mediated by stimulation of $\mathrm{K}_{\mathrm{V}}$ channels (Jarajapu et al. 2006). Thus, the lower maximum contractile effects of His, when compared with those of 5$\mathrm{HT}$ and $\mathrm{KCl}$, may be due to the activation of different receptor types and pathways. Histamine seems to activate $\mathrm{H}_{2}$ receptors mediating vasorelaxation that could decrease the contractile effect induced by $\mathrm{H}_{1}$ activation, even if the latter effect is predominant. On the other hand, $\mathrm{H}_{1}$ - and $\mathrm{H}_{2}$ receptor activation by $\mathrm{His}$ seems to stimulate potassium channels whereas 5-HT and $\mathrm{KCl}$ have the opposite actions and this could explain the greater contractile effect of 5-HT and $\mathrm{KCl}$ on HUA.

Our results show that Tes induces a concentrationdependent relaxation of denuded HUA rings contracted with either 5-HT, His or $\mathrm{KCl}(30$ and $60 \mathrm{mM})$. The maximum relaxation was obtained at $100 \mu \mathrm{M}$ of Tes and was similar in HUA contracted by $\mathrm{His}$ and $\mathrm{KCl}$ (30 and $60 \mathrm{mM}$ ). Lower maximum relaxation was obtained in 5HT-contracted arteries. These results differ from those obtained by Fausset et al. that showed a much lower degree of relaxation $(9.2 \%)$ in $\mathrm{KCl}$-contracted intact HUA (Fausett et al. 1999). The maximum Tes-associated effects described in the literature for other arteries contracted with $\mathrm{KCl}$ are diverse, but there are no data regarding His- and 5HT-contracted arteries. Despite the maximum Tes-associated effect, the relaxation induced by lower concentrations of Tes $(1-30 \mu \mathrm{M})$ is significantly greater for His-contracted arteries. These different effects, which depend upon the contractile agent used, could give some indications as to what mechanisms might be involved in Tes-induced relaxation.

One of the pathways implicated in 5-HT contractility is the inhibition of adenylyl cyclase, whereas the phospholypase C pathway is implicated in both His and 5-HT contractile effects. Could the inhibition of adenylyl cyclase by 5 -HT be responsible for the lower effect of Tes on the arteries contracted by this agent? There are no data in the literature to support the hypothesis that Tes-associated effects are mediated by adenylyl cyclase activation. On the other hand, $\mathrm{KCl}$ induces depolarisation of the smooth muscle cell membrane by opening calcium channels. Could the cell membrane hyperpolarisation be implicated in the Tes mechanism for induction of vascular relaxation? Some authors suggested that Tes stimulates potassium channels in rat aorta (Honda et al. 1999) and also in rabbit (Won et al. 2003) and pig (Deenadayalu et al. 2001) coronary arteries. Other authors demonstrated a blockage of calcium channels by Tes in the aorta (Perusquia et al. 1996) and coronary artery (Jones et al. 2004) of rats.

As mentioned above, some authors showed that inhibition of potassium channels is induced by 5-HT (Bae et al. 2006; Cogolludo et al. 2006) and $\mathrm{KCl}$ (Jarajapu et al. 2006), whereas theses channels are stimulated by His 
(Jarajapu et al. 2006). Could the effect of contractile agents on potassium channels be responsible for the different actions of Tes on contractions induced by each one? If the Tes-associated vasorelaxant mechanism is due to the activation of potassium channels, the effect of Tes on 5HT- and $\mathrm{KCl}$-induced contractions will be lower than that on His-induced contractions. If the vasorelaxant mechanism of Tes is only due to blockage of calcium channels, the effect of Tes on 5-HT- and KCl-induced contractions will be similar. In this regard, our results could indicate that Tes relaxes by activating potassium channels, in agreement with the results in different blood vessels obtained by other authors (Deenadayalu et al. 2001; Honda et al. 1999; Won et al. 2003).

On the other hand, high extracellular $\mathrm{KCl}$ reduces the chemical gradient for $\mathrm{K}$ efflux and could reduce or avoid the effect of Tes on $\mathrm{KCl}$ contraction, which will be lower than that on agonist-contracted arteries. In accordance with this, some investigators did not obtain Tes-induced relaxation on KCl-contracted arteries (Fausett et al. 1999; Tepareenan et al. 2002). However, other authors had reliable maximum relaxation with $\mathrm{KCl}$-induced contractions, namely $50 \%$ in rat aorta (Ding and Stallone 2001), $40 \%$ in rabbit coronary artery (Yue et al. 1995), 80\% in human subcutaneous artery (Malkin et al. 2006) and 100\% in rat coronary artery (Jones et al. 2004). Our results show identical vasodilatation induced by different Tes concentrations (1$100 \mu \mathrm{M})$ when two concentrations of $\mathrm{KCl}(30$ and $60 \mathrm{mM})$ were used to pre-constrict HUA. Jones et al. observed the same Tes effect in rat coronary artery using various concentrations of $\mathrm{KCl}$ to pre-constrict the vessels (Jones et al. 2004). These observations suggest that extracellular potassium concentration and the depolarisation degree have no influence on the vasodilator efficacy of Tes. Regardless of the mechanism, it is clear that testosterone modulates the excitability of vascular smooth muscle, and our data provide evidence that this steroid opens potassium channels in HUA. Thus, our study focused on the role of different types of potassium channels in the vasorelaxant mechanism of Tes.

Testosterone is a sex steroid hormone, and the interaction of these hormones with intracellular receptors has long been known to stimulate genomic effects that could influence vascular cell growth and proliferation. Concerning the non-genomic effects, some studies indicated the participation of the intracellular receptor and others suggested that the effects are independent of this receptor (Falkenstein et al. 2000). Our findings show that Tesinduced vasorelaxation was not inhibited by a Tes intracellular receptor antagonist, suggesting that the vasorelaxation is mediated via another receptor or pathway. These results are in agreement with previous studies in coronary artery and aorta of rabbit (Yue et al. 1995) and in mesenteric artery (Tep-areenan et al. 2002) and aorta (Tep-areenan et al. 2003) of rat, which also showed that Tes-induced vasorelaxation is unaffected by flutamide. In contrast, Murphy et al. showed that Tes-associated relaxant effect in pig coronary artery is inhibited by flutamide (Murphy and Khalil 1999). In order to explain these differences, some authors suggested that species and/or regional differences may involve differential distributions of steroid hormone receptors (Tep-areenan et al. 2002; Tep-areenan et al. 2003). A large number of studies have reported Tesinduced vasorelaxation in animal (Crews and Khalil 1999; Deenadayalu et al. 2001; Perusquia and Villalon 1999; Perusquia et al. 1996; Yue et al. 1995) and human arteries (Yildiz et al. 2005) without endothelium. Our results in HUA confirm that Tes induces vasorelaxation independently of the endothelium, and this effect is not mediated via a classic intracellular receptor-dependent mechanism.

The inhibitors of potassium channels did not have any effect on 5-HT-, His- or $\mathrm{KCl}(60 \mathrm{mM})$-contracted arteries. However, incubation with Gli, 4-AP and TEA together reduced the Tes-induced $(100 \mu \mathrm{M})$ relaxation effects for all contractile agents used. These results agree with a previous study in rabbit coronary arteries and thoracic aorta, where barium chloride, an unspecific inhibitor of potassium channels, reduced the Tes-associated relaxation effects (Yue et al. 1995). These findings strongly suggest that opening potassium channels results in hyperpolarisation of the vascular cell membranes and closing of the voltagedependent calcium channels. In this regard, some authors suggested that Tes inhibits calcium influx through calcium channels in different blood vessels (Crews and Khalil 1999; Jones et al. 2002; Murphy and Khalil 1999; Perusquia and Villalon 1999; Scragg et al. 2004). However, as potassiumchannel inhibition did not completely abolish this relaxation, other mechanisms are presumably involved.

The Tes-induced relaxation on 5-HT-associated contractions was significantly inhibited by $\mathrm{K}_{\mathrm{V}}$ and $\mathrm{BK}_{\mathrm{Ca}}$ channel inhibitors, suggesting the participation of these channels in Tes relaxant mechanism. Similar data were obtained by Yue et al. in prostaglandin $\mathrm{F}_{2 \text { alpha-contracted rabbit coronary }}$ artery (Yue et al. 1995).

Testosterone-induced relaxation on His-associated contraction was principally inhibited by $4-\mathrm{AP}$, and the effect observed with this selective blocker is similar to the effect obtained by the application of all blockers together, indicating that Tes may cause vasorelaxation mainly via $\mathrm{KV}$ in His-contracted HUA. The involvement of $\mathrm{K}_{\mathrm{V}^{-}}$ channel activation in Tes-induced vasorelaxation of rat aorta contracted with phenylephrine was also suggested by Ding and Stallone (2001).

The effect of Tes on KCl-induced contraction was significantly inhibited by TEA, but not by Gli or 4-AP, indicating that Tes-associated vasorelaxation is mainly 
caused by $\mathrm{BK}_{\mathrm{Ca}}$ activation in $\mathrm{HUA}$ contracted with $\mathrm{KCl}$. In agreement with this data, Yildiz et al. demonstrated that TEA inhibits vasorelaxation induced by Tes in internal mammary artery rings contracted with $\mathrm{KCl}$ (Yildiz et al. 2005). Some authors also suggested that Tes opens $B K_{C a}$ in the rat mesenteric arterial bed (Tep-areenan et al. 2002) and rat aorta (Tep-areenan et al. 2003), inducing relaxation of KCl-associated contractions. Moreover, Deenadayalu et al. demonstrated by patch-clamp studies that testosterone opens $\mathrm{BK}_{\mathrm{Ca}}$ channels in porcine coronary smooth muscle cells, and also suggested that these channels are activated by a smooth muscle cell source of cGMP (Deenadayalu et al. 2001). Further investigations are needed to analyse the role of cyclic nucleotides on Tes-associated vascular effects.

Thus, our results indicate that the activation of $\mathrm{K}_{\mathrm{V}}$ and $\mathrm{BK}_{\mathrm{Ca}}$ channels is involved in the relaxant effects of Tes, and the participation of these two channels was dependent on the contractile agent used. The present data indicate that the effects of Tes on $\mathrm{KCl}$-induced contractions are due to $\mathrm{BK}_{\mathrm{Ca}}$ but not to $\mathrm{K}_{\mathrm{V}}$ activation. Lack of relevance of $\mathrm{K}_{\mathrm{V}}$ in this case might be explained by the effects of $\mathrm{KCl}$ on vascular smooth muscle. Jarajapu et al. showed that $\mathrm{Kv}$ channels are inactivated at high concentrations of $\mathrm{KCl}$ (60 mM) (Jarajapu et al. 2006), in which case the $K_{V}$ open probability induced by Tes would be lower and the contribution of these channels towards the Tes-associated relaxant effect on $\mathrm{KCl}$-contracted HUA would be not significant. Some authors also demonstrated that 5-HT decreases $\mathrm{Kv}$ current in smooth muscle cells (Bae et al. 2006; Cogolludo et al. 2006). However our results in 5-HTcontracted arteries show that activation of both $\mathrm{K}_{\mathrm{V}}$ and $\mathrm{BK}_{\mathrm{Ca}}$ channels is involved in Tes vasorelaxation. Maybe Tes can reverse the decrease in activity induced by $5-\mathrm{HT}$ on these channels and is unable to reverse the $\mathrm{K}_{\mathrm{V}}$-channels inactivation induced by $\mathrm{KCl}$. In contrast, Jarajapu et al. suggested a functional coupling of $\mathrm{H}_{2}$ receptors to $\mathrm{K}_{\mathrm{V}}$ channels that activates these channels (Jarajapu et al. 2006). As previously mentioned, we associated the effect of contractile agents on potassium channels with the greater Tes-induced relaxation on His contraction when compared with $5-\mathrm{HT}$ or $\mathrm{KCl}$ contractile actions. Our data show that activation of $\mathrm{K}_{\mathrm{V}}$ is involved in Tes-induced relaxation in HUA contracted by His. Probably, after exposure to His, a further activation of $\mathrm{K}_{\mathrm{V}}$ by Tes is responsible for a greater relaxation of HUA obtained with this agonist. Nevertheless, the reason why $\mathrm{BK}_{\mathrm{Ca}}$ channels are not significantly involved in Tes vasorelaxation of HUA contracted by His remains unknown, and further research using electrophysiological techniques needs to be performed.

In summary, the primary goal of this study was to determine the effects of testosterone on HUA without endothelium. We have shown that Tes induces vasorelaxation of these arteries and our results suggest that this effect is not mediated via the classic intracellular Tes-receptor-dependent mechanism. This relaxation appears to be partially mediated by activation of $\mathrm{BK}_{\mathrm{Ca}^{-}}$and $\mathrm{K}_{\mathrm{V}}$-channel activation. The involvement of these two channels in the Tes relaxant mechanism is dependent on the pathways activated by the contractile agent used. Further investigations are needed to identify the signalling mechanisms that couple testosterone receptor activation to potassium channel stimulation.

Acknowledgements We thank the donor mothers and the Gynaecology-Obstetrics Department staff of Centro Hospitalar da Cova da Beira (Covilhã, Portugal) for their collaboration and the Fundação para a Ciência e a Tecnologia (Portugal) for supporting the fellowship grants SFRH/BPD/14458/2003 and SFRH/BDE/ $15532 / 2004$.

\section{References}

Alexandersen P, Haarbo J, Christiansen C (1996) The relationship of natural androgens to coronary heart disease in males: a review. Atherosclerosis 125:1-13

Bae YM, Kim A, Kim J, Park SW, Kim TK, Lee YR, Kim B, Cho SI (2006) Serotonin depolarizes the membrane potential in rat mesenteric artery myocytes by decreasing voltage-gated $\mathrm{K}+$ currents. Biochem Biophys Res Commun 347:468-476

Chou TM, Sudhir K, Hutchison SJ, Ko E, Amidon TM, Collins P, Chatterjee K (1996) Testosterone induces dilation of canine coronary conductance and resistance arteries in vivo. Circulation 94:2614-2619

Cogolludo A, Moreno L, Lodi F, Frazziano G, Cobeno L, Tamargo J, Perez-Vizcaino F (2006) Serotonin inhibits voltage-gated K+ currents in pulmonary artery smooth muscle cells: role of 5HT2A receptors, caveolin-1, and KV1.5 channel internalization. Circ Res 98:931-938

Crews JK, Khalil RA (1999) Antagonistic effects of 17 beta-estradiol, progesterone, and testosterone on $\mathrm{Ca}^{2+}$ entry mechanisms of coronary vasoconstriction. Arterioscler Thromb Vasc Biol 19:1034-1040

Deenadayalu VP, White RE, Stallone JN, Gao X, Garcia AJ (2001) Testosterone relaxes coronary arteries by opening the largeconductance, calcium-activated potassium channel. Am J Physiol Heart Circ Physiol 281:H1720-H1727

Ding AQ, Stallone JN (2001) Testosterone-induced relaxation of rat aorta is androgen structure specific and involves $\mathrm{K}+$ channel activation. J Appl Physiol 91:2742-2750

English KM, Jones RD, Jones TH, Morice AH, Channer KS (2000a) Aging reduces the responsiveness of coronary arteries from male Wistar rats to the vasodilatory action of testosterone. Clin Sci (Lond) 99:77-82

English KM, Mandour O, Steeds RP, Diver MJ, Jones TH, Channer KS (2000b) Men with coronary artery disease have lower levels of androgens than men with normal coronary angiograms. Eur Heart J 21:890-894

English KM, Steeds RP, Jones TH, Diver MJ, Channer KS (2000c) Lowdose transdermal testosterone therapy improves angina threshold in men with chronic stable angina: a randomized, double-blind, placebo-controlled study. Circulation 102:1906-1911

Falkenstein E, Tillmann HC, Christ M, Feuring M, Wehling M (2000) Multiple actions of steroid hormones-a focus on rapid, nongenomic effects. Pharmacol Rev 52:513-556 
Fausett MB, Belfort MA, Nanda R, Saade GR, Vedernikov Y (1999) The effects of sex steroids on human umbilical artery and vein. $\mathrm{J}$ Soc Gynecol Investig 6:27-31

Gerulewicz-Vannini D, Camero Y, Salas J, Hernandez-Andrade E (2006) [High plasmatic androgen levels in women affected with pregnancy-induced hypertension]. Rev Invest Clin 58:228-233

Hall J, Jones RD, Jones TH, Channer KS, Peers C (2006) Selective inhibition of L-type $\mathrm{Ca}^{2+}$ channels in A7r5 cells by physiological levels of testosterone. Endocrinology 147:2675-2680

Hawley J, Rubin PC, Hill SJ (1995) Distribution of receptors mediating phosphoinositide hydrolysis in cultured human umbilical artery smooth muscle and endothelial cells. Biochem Pharmacol 49:1005-1011

Honda H, Unemoto T, Kogo H (1999) Different mechanisms for testosterone-induced relaxation of aorta between normotensive and spontaneously hypertensive rats. Hypertension 34:12321236

Jahnichen S, Glusa E, Pertz HH (2005) Evidence for 5-HT2B and 5HT7 receptor-mediated relaxation in pulmonary arteries of weaned pigs. Naunyn Schmiedebergs Arch Pharmacol 371:8998

Jarajapu YP, Oomen C, Uteshev VV, Knot HJ (2006) Histamine decreases myogenic tone in rat cerebral arteries by H2-receptormediated KV channel activation, independent of endothelium and cyclic AMP. Eur J Pharmacol 547:116-124

Jones RD, English KM, Pugh PJ, Morice AH, Jones TH, Channer KS (2002) Pulmonary vasodilatory action of testosterone: evidence of a calcium antagonistic action. J Cardiovasc Pharmacol 39:814-823

Jones RD, English KM, Jones TH, Channer KS (2004) Testosteroneinduced coronary vasodilatation occurs via a non-genomic mechanism: evidence of a direct calcium antagonism action. Clin Sci (Lond) 107:149-158

Leung SW, Quan A, Lao TT, Man RY (2006) Efficacy of different vasodilators on human umbilical arterial smooth muscle under normal and reduced oxygen conditions. Early Hum Dev 82:457462

Lovren F, Li XF, Lytton J, Triggle C (1999) Functional characterization and m-RNA expression of 5-HT receptors mediating contraction in human umbilical artery. $\mathrm{Br} \mathrm{J}$ Pharmacol 127:1247-1255

Malkin CJ, Jones RD, Jones TH, Channer KS (2006) Effect of testosterone on ex vivo vascular reactivity in man. Clin Sci (Lond) 111:265-274

Murphy JG, Khalil RA (1999) Decreased $\left[\mathrm{Ca}^{2+}\right]_{\mathrm{i}}$ during inhibition of coronary smooth muscle contraction by 17 beta-estradiol, progesterone, and testosterone. J Pharmacol Exp Ther 291:44-52

Orshal JM, Khalil RA (2004) Gender, sex hormones, and vascular tone. Am J Physiol Regul Integr Comp Physiol 286:R233-R249

Pasqualini JR (2005) Enzymes involved in the formation and transformation of steroid hormones in the fetal and placental compartments. J Steroid Biochem Mol Biol 97:401-415

Pauwels PJ (2000) Diverse signalling by 5-hydroxytryptamine (5-HT) receptors. Biochem Pharmacol 60:1743-1750
Perusquia M, Villalon CM (1999) Possible role of $\mathrm{Ca}^{2+}$ channels in the vasodilating effect of 5beta-dihydrotestosterone in rat aorta. Eur J Pharmacol 371:169-178

Perusquia M, Hernandez R, Morales MA, Campos MG, Villalon CM (1996) Role of endothelium in the vasodilating effect of progestins and androgens on the rat thoracic aorta. Gen Pharmacol 27:181-185

Pinthus JH, Trachtenberg J, Klotz L (2006) Cardiovascular effects of androgen depletion and replacement therapy. Urology 67:11261132

Quan A, Leung SW, Lao TT, Man RY (2003) 5-hydroxytryptamine and thromboxane A2 as physiologic mediators of human umbilical artery closure. J Soc Gynecol Investig 10:490-495

Salamalekis E, Bakas P, Vitoratos N, Eleptheriadis M, Creatsas G (2006) Androgen levels in the third trimester of pregnancy in patients with preeclampsia. Eur J Obstet Gynecol Reprod Biol 126:16-19

Schneider A, Riess P, Elbers A, Neugebauer E, Schaefer U (2004) Polyclonal anti-histamine $\mathrm{H} 2$ receptor antibodies detect differential expression of $\mathrm{H} 2$ receptor protein in primary vascular cell types. Inflamm Res 53:223-229

Scragg JL, Jones RD, Channer KS, Jones TH, Peers C (2004) Testosterone is a potent inhibitor of L-type $\mathrm{Ca}^{2+}$ channels. Biochem Biophys Res Commun 318:503-506

Steinert JR, Wyatt AW, Poston L, Jacob R, Mann GE (2002) Preeclampsia is associated with altered $\mathrm{Ca}^{2+}$ regulation and NO production in human fetal venous endothelial cells. FASEB J $16: 721-723$

Tammaro P, Smith AL, Hutchings SR, Smirnov SV (2004) Pharmacological evidence for a key role of voltage-gated $\mathrm{K}^{+}$channels in the function of rat aortic smooth muscle cells. Br J Pharmacol 143:303-317

Tep-areenan P, Kendall DA, Randall MD (2002) Testosterone-induced vasorelaxation in the rat mesenteric arterial bed is mediated predominantly via potassium channels. Br J Pharmacol 135:735-740

Tep-areenan P, Kendall DA, Randall MD (2003) Mechanisms of vasorelaxation to testosterone in the rat aorta. Eur $\mathrm{J}$ Pharmacol 465:125-132

Terron JA, Falcon-Neri A (1999) Pharmacological evidence for the 5HT7 receptor mediating smooth muscle relaxation in canine cerebral arteries. Br J Pharmacol 127:609-616

Tufan H, Ayan-Polat B, Tecder-Unal M, Polat G, Kayhan Z, Ogus E (2003) Contractile responses of the human umbilical artery to $\mathrm{KCl}$ and serotonin in Ca-free medium and the effects of levcromakalim. Life Sci 72:1321-1329

Won E, Won J, Kwon S, Lee Y, Nam T, Ahn D (2003) Testosterone causes simultaneous decrease of $\left[\mathrm{Ca}^{2+}\right]_{\mathrm{i}}$ and tension in rabbit coronary arteries: by opening voltage dependent potassium channels. Yonsei Med J 44:1027-1033

Yildiz O, Seyrek M, Gul H, Un I, Yildirim V, Ozal E, Uzun M, Bolu E (2005) Testosterone relaxes human internal mammary artery in vitro. J Cardiovasc Pharmacol 45:580-585

Yue P, Chatterjee K, Beale C, Poole-Wilson PA, Collins P (1995) Testosterone relaxes rabbit coronary arteries and aorta. Circulation 91:1154-1160 